\title{
L'HOMME L'Homme
}

Revue française d'anthropologie

164 | octobre-décembre 2002

Histoire, littérature et ethnologie

\section{Jacques Rancière, La Fable cinématographique}

Paris, Le Seuil, 2001, 245 p., index, ill. (« La librairie du Xx siècle »)

Jean-Louis Siran

\section{OpenEdition}

Journals

Édition électronique

URL : https://journals.openedition.org//homme/195

DOI : $10.4000 /$ /homme.195

ISSN : 1953-8103

Éditeur

Éditions de l'EHESS

\section{Édition imprimée}

Date de publication : 1 décembre 2002

Pagination : 155-156

ISBN : 2-7132-1775-X

ISSN : 0439-4216

Référence électronique

Jean-Louis Siran, " Jacques Rancière, La Fable cinématographique », L'Homme [En ligne], 164 | octobredécembre 2002, mis en ligne le 25 mars 2008, consulté le 23 avril 2022. URL : http://

journals.openedition.org//homme/195; DOI : https://doi.org/10.4000/lhomme.195

Ce document a été généré automatiquement le 23 avril 2022

(c) École des hautes études en sciences sociales 


\title{
Jacques Rancière, La Fable cinématographique
}

Paris, Le Seuil, 2001, 245 p., index, ill. (« La librairie du Xx ${ }^{\mathrm{e}}$ siècle »)

\author{
Jean-Louis Siran
}

1 CE LIVRE est une collection d'articles. Plusieurs d'entre eux sont autant de brèves monographies sur l'art de Murnau, Fritz Lang ou Nicholas Ray. J'ai particulièrement aimé l'essai consacré à Anthony Mann : à ce passant qu'incarne, de film en film, un James Stewart fragile et pourtant comme invulnérable, car il a « la distance de celui qui connaît les gestes et les codes mais ne peut plus partager les rêves et les leurres " (p. 121). Cette distance est celle d'Anthony Mann par rapport à un genre, le western, qu'il exemplifie dans le respect le plus exact des figures imposées: "arrivée de cavaliers étrangers dans une petite ville en effervescence, provocation dans un saloon, partie de poker qui finit mal, poursuite dans le désert», etc., etc. (p. 105). Tous les termes du contrat implicite avec le spectateur qui vient voir un western sont ici respectés (à la différence de ce qu'il en advient chez quelques reconvertis du peplum) : le contrat est bien honoré, et le genre choyé, mais d'une tendresse toute nostalgique.

2 Je ne résisterai pas à un jeu de mot facile mais pertinent: Mann, c'est « l'été indien » du western. Et Stewart n'en est plus le héros mais la figure, la figure endeuillée qui se protège de la souffrance dans la mise à distance prudente de qui ménage ses affects. Tout cela, Jacques Rancière le dit admirablement, mieux et en d'autres mots, dans l'analyse rigoureuse de quelques séquences où L'Appât, L'Homme de l'Ouest et The Far Country sont examinés de très près.

Bien. Mais je n'écris pas ce compte rendu pour Positif ou les Cahiers du cinéma. En quoi ce livre devrait-il intéresser un lecteur de L'Homme ? En ceci qu'il s'affronte au muthos et à la mimesis. Rancière ne fait pas semblant d'avoir lu Aristote. On l'imagine mal parlant de "mytho-poétique »! Car le muthos aristotélicien n'a rien à voir avec le "mythique » de nos traditions anthropologiques. Il en est même l'opposé : c'est tout simplement la mise en intrigue (Ricœur l'a vu et montré) d'histoires jusque-là en attente. Et c'est bien à ce muthos là que s'intéresse, ou plutôt s'oppose Rancière, cet amoureux de cinéma déçu de ce que celui-ci ait trop vite renoncé au pouvoir propre de l'image pour la 
soumettre «aux "histoires" que lui proposaient les scénarios, hérités de la tradition littéraire de l'intrigue et des personnages » (p. 217).

4 Sa critique vise beaucoup plus loin que l'industrie hollywoodienne «qui a réduit les créateurs cinématographiques au rôle d'illustrateurs de scénarios fondés, à des fins de rentabilité commerciale, sur la standar-disation des intrigues et l'identification aux personnages » (p. 10). Cette critique-là, pour fondée qu'elle soit, est bien sûr trop facile. C'est d'un deuil plus ancien que Rancière nous entretient. Deuil de cette « utopie » des années vingt, utopie d'un monde «électrique " (attribuée à Jean Epstein) selon laquelle «l'art des images mobiles » ne serait pas seulement « une technique de la visibilité qui aurait remplacé l'art d'imiter les formes visibles» (p. 8), mais bien plutôt «l'accès ouvert à une vérité intérieure du sensible » où s'abolirait «toute opposition entre les apparences trompeuses et la réalité substantielle» (p. 9).

Une telle utopie ne fut jamais celle de Rancière. C'est lui qui le dit. Mais c'est quand même un peu comme s'il n'arrivait pas à y renoncer. D'où un certain malaise du lecteur, à ne jamais très bien savoir d'où lui parle l'auteur. Et c'est là qu'on regrette que Rancière ne s'essaie pas davantage à élaborer un peu plus ce désir qui l'habite d'un cinéma non narratif. Vient donc à la place un texte consacré à commenter deux ouvrages de Deleuze ${ }^{1}$. J'avoue n'y avoir à peu près rien compris (au point de n'avoir même pas envie de le relire pour savoir à qui la faute, de Deleuze, Rancière ou moi). On trouvera encore deux articles consacrés à Godard. Parfaitement intelligibles ceux-là, et que ceux qui aiment ou prennent encore Godard au sérieux qu'il affiche apprécieront sans aucun doute. Les autres y trouveront au moins, mais comme en creux, l'idée, ambitieuse et forte, que, loin des normes actuelles, Rancière se fait du cinéma.

On ne manquera pas de signaler ici que ce livre rencontre au plus près le «faire » d'un certain nombre d'entre nous lorsqu'il aborde, à propos de Chris Marker, la question du documentaire pour rappeler que " la fiction » ne s'oppose pas à la "réalité » et qu'en retour un «film documentaire n'est pas le contraire d'un film de fiction» (p.202). Il est aussi des pages tout à fait lucides et pertinentes, mais qui ne manqueront pas d'avoir un goût amer pour ceux qui fréquentèrent la Cinémathèque dans les années soixante. Ce sont celles qu'il consacre à Eisenstein. Où il est en effet montré que des films tels Le Cuirassé Potemkine ou La Ligne générale ne visaient certes pas à susciter l'identification du spectateur à un quelconque personnage, mais qu'à travers le choc de deux plans, loin des "nuances de la tradition mimétique», il s'agissait d'atteindre "directement le système nerveux» par des "opérations formelles» (le montage) qui assurent l'adéquation entre « le pur calcul conscient de l'œuvre » et « la logique inconsciente qui gouverne les couches les plus profondes de la pensée sensorielle » (pp. 31-37). Rancière oppose ici, de manière tout à fait convaincante, la démarche de Brecht qui prétendait " purger la représentation théâtrale " pour " apprendre à voir et à mettre à distance ", à celle d'Eisenstein pour qui "un art communiste " était «un art extatique, transformant directement les connexions d'idées en chaînes d'images » (p. 40).

Il faut lire Rancière, et revoir Los Hurdes. 


\section{NOTES}

1. Gilles Deleuze, L'Image-mouvement, Paris, Éditions de Minuit, 1983 («Critique») et L'Image-temps, Paris, Éditions de Minuit, 1985 («Critique»).

\section{AUTEUR}

\section{JEAN-LOUIS SIRAN}

CNRS, Paris. 